\title{
Targeting glucosylceramide synthase sensitizes imatinib-resistant chronic myeloid leukemia cells via endogenous ceramide accumulation
}

\author{
Yusuf Baran · Jacek Bielawski · Ufuk Gunduz • \\ Besim Ogretmen
}

Received: 4 July 2011 / Accepted: 20 July 2011 / Published online: 11 August 2011

(C) Springer-Verlag 2011

\begin{abstract}
Purpose Drug resistance presents a major obstacle for the treatment of some patients with chronic myeloid leukemia (CML). Pro-apoptotic ceramide mediates imatinib-induced apoptosis, and metabolism of ceramide by glucosylceramide synthase (GCS) activity, converting ceramide to glucosyl ceramide, might contribute to imatinib resistance. In this study, we investigated the role of ceramide metabolism by GCS in the regulation of imatinib-induced apoptosis in drug-sensitive and drug-resistant K562 and K562/IMA-0.2 and K562/IMA-1 human CML cells, which exhibit about 2.3- and 19-fold imatinib resistance, respectively.

Methods Cytotoxic effects of PDMP and imatinib were determined by XTT cell proliferation assay. Expression levels of GCS were determined by RT-PCR and western blot. Intracellular ceramide levels were determined by LCMS. Cell viability analyses was conducted by Trypan blue
\end{abstract}

Y. Baran ( $\square)$

Department of Molecular Biology and Genetics,

Izmir Institute of Technology, Faculty of Science,

Gulbahce Campus, 35430 Urla, Izmir, Turkey

e-mail: yusufbaran@iyte.edu.tr

J. Bielawski · B. Ogretmen

Department of Biochemistry and Molecular Biology,

Medical University of South Carolina,

Charleston, SC 29425, USA

U. Gunduz

Department of Biology,

Middle East Technical University,

06531 Ankara, Turkey dye exclusion assay. Cell cycle and apoptosis analyses were examined by flow cytometry.

Results We first showed that mRNA and protein levels of GCS are increased in drug-resistant K562/IMA as compared to sensitive K562 cells. Next, forced expression of GCS in sensitive K562 cells conferred resistance to imatinib-induced apoptosis. In reciprocal experiments, targeting GCS using its known inhibitor, PDMP, enhanced ceramide accumulation and increased cell death in response to imatinib in K562/IMA cells.

Conclusion Our data suggest the involvement of GCS in resistance to imatinib-induced apoptosis, and that targeting GCS by PDMP increased imatinib-induced cell death in drug-sensitive and drug-resistant K562 cells via enhancing ceramide accumulation.

Keywords Ceramide $\cdot$ Apoptosis $\cdot$ Glucosylceramide . Drug resistance $\cdot \mathrm{CML}$

\begin{tabular}{|c|c|}
\hline \multicolumn{2}{|l|}{ Abbreviations } \\
\hline CML & Chronic myeloid leukemia \\
\hline IMA & Imatinib \\
\hline MDR & Multiple drug resistance \\
\hline $\begin{array}{l}\text { K562/IMA-0.2 } \\
\text { and K562/IMA-1 }\end{array}$ & $\begin{array}{l}\text { K562 cells those were able to grow in } \\
\text { the presence of } 0.2 \text { and } 1 \mu \mathrm{M} \text { Imatinib }\end{array}$ \\
\hline GCS & Glucosylceramide synthase \\
\hline GlcCer & Glucosylceramide \\
\hline$(\mathrm{IC})_{50}$ & $\begin{array}{l}\text { The concentration of any chemical that } \\
\text { inhibits growth by } 50 \%\end{array}$ \\
\hline XTT & $\begin{array}{l}\text { 2,3-bis-(2-methoxy-4-nitro-5-sulfophe- } \\
\text { nyl)-2H-tetrazolium-5-carboxanilide }\end{array}$ \\
\hline RT-PCR & $\begin{array}{l}\text { Reverse transcriptase-polymerase } \\
\text { chain reaction }\end{array}$ \\
\hline $\mathrm{Pi}$ & Inorganic phosphate \\
\hline LC/MS & $\begin{array}{l}\text { LC/MSLiquid chromatography-mass } \\
\text { spectrometry }\end{array}$ \\
\hline
\end{tabular}




\section{Introduction}

A major advancement in the treatment of chronic myeloid leukemia (CML) has been the development of imatinib, which has shown striking activity in the chronic phase and the accelerated phase, but less so in the blast phase of the disease (Buchdunger et al. 1996). Despite high rates of hematologic and cytogenetic responses to therapy, the emergence of resistance to imatinib has been recognized as a major problem in the treatment of patients with CML (Deininger 2005; Hegedus et al. 2002; Krystal 2001; Koca and Haznedaroglu 2005; Walz and Sattler 2006).

Resistance to anticancer agents can be explained by a number of mechanisms including decreased uptake, increased detoxification, and alteration of target proteins or increased excretion. Even if anticancer drugs reach their sites of action, by passing drug efflux system of the cells, some cells still survive via the inhibition of pro-apoptotic signaling (Robertson et al. 1993). It has been well known that multidrug-resistant (MDR) cells show cross-resistance not only to anticancer agents but also to pro-apoptotic stresses including tumor necrosis factor $\alpha$, irradiation, antiFas antibody cross-linking, and serum starvation (Bradshaw and Arceci 1998). These suggest the possibility that dysregulation of apoptotic signaling plays a very important role in MDR (Hale et al. 1996).

Sphingolipids are a family of membrane lipids with important roles not only in the regulation of the fluidity and sub-domain structure of the lipid bilayer but also in many aspects of cell biology, from inflammatory responses through cell proliferation and apoptosis to cell migration and senescence (Ogretmen and Hannun 2004). Many sphingolipid-regulated functions have significant and specific links to various aspects of cancer initiation, progression, and response to anticancer treatments. Ceramide, an effector molecule in apoptotic signaling, plays a principal role in the nature of cellular response to anticancer therapies and other stress-causing agonists (Hannun and Obeid 2002; Kolesnick and Kronke 1998). The levels of intracellular pro-apoptotic ceramide were shown to be increased by anticancer drugs and stresses in cancer cells (Hannun 1996; Okazaki et al. 1998; Sawai et al. 1997). It was also shown previously by different groups that increased ceramide levels enhance the efficacy of vinblastine (Cabot et al. 1999), Adriamycin, daunorubicin, actinomycin D (Bose et al. 1995; Dbaibo et al. 1998; Liu et al. 1999), and taxol (Myrick et al. 1999).

On the other hand, alterations of the accumulation of ceramide via its increased metabolism to glucosylceramide (GlcCer) by glucosyceramide synthase (GCS) are a characteristic of various MDR cancer cells of colon, breast, ovarian, and epithelioid carcinomas (Kok et al. 2000; Lavie et al. 1996; Nicholson et al. 1999). Lucci and co-workers showed that GlcCer levels are elevated in tumor specimens from patients with breast cancer and melanoma who demonstrated poor response to chemotherapy (Lucci et al. 1998). The enzyme GCS transfers glucose from UDP-glucose to ceramide and produces GlcCer. GCS appears to have important functions over cell growth and apoptosis. It was shown that GlcCer induces tumor growth (Perales et al. 1998) and cell proliferation (Marsh et al. 1995) while inhibition of GCS results in cell death, effect, inhibition of cell division (Kyogashima et al. 1996), and reduction of metastasis (Inokuchi et al. 1990). However, involvement of increased ceramide metabolism by GCS in the regulation of imatinib-induced apoptosis and/or resistance in CML has not been reported previously.

In our previous study, we reported that increased generation of ceramide mediates imatinib-induced apoptosis, and overexpression of sphingosine kinase 1 (SK1) results in imatinib resistance in K562 cells via modulation of ceramide/S1P rheostat (Baran et al. 2007). Since glycosylation of ceramide by GCS emerges as a novel mechanism of drug resistance (Liu et al. 1999, 2000; Kok et al. 2000), we hypothesized that targeting GCS might be a novel strategy to overcome resistance to imatinib-induced cell death via restoring ceramide accumulation in CML cells.

In this study, our goal was to identify the role of ceramide metabolism by GCS in imatinib resistance, and to explore whether targeting GCS using its known inhibitor, D-threo-1-phenyl-2-decanoylamino-3-morpholino-1-propanol (PDMP), presents a novel approach to reverse drug resistance in human K562 CML cells. Our data suggested that GCS expression at both mRNA and protein levels was increased significantly in drug-resistant K562/IMA-0.2 and K562/IMA-1 cells as compared to parental and drug-sensitive K562 cells. Importantly, while forced expression of GCS inhibited imatinib-induced cell death in sensitive K562 cells, targeting GCS by PDMP in drug-resistant K562/IMA cells increased apoptosis in response to imatinib, which was consistent with elevation of endogenous ceramide levels, measured by Lipidomics. Thus, these data indicate that increased metabolism of ceramide by GCS is involved in the inhibition of imaitnib-induced cell death, and that targeting GCS by PDMP partially reverses drug resistance in K562/IMA cells via elevation of pro-apoptotic ceramide accumulation.

\section{Materials and methods}

Cell lines and culture conditions

The Philadelphia $(\mathrm{Ph})$ chromosome-positive K562 human CML cells were obtained from German Collection of 
Microorganisms and Cell Cultures and maintained in RPMI 1640 growth medium containing $10 \%$ fetal bovine serum and $1 \%$ penicillin-streptomycin (Invitrogen, USA) at $37^{\circ} \mathrm{C}$ in $5 \% \mathrm{CO}_{2}$.

\section{Selection of imatinib-resistant K562 cells}

We generated imatinib-resistant sublines of K562 cells that could grow in the presence of 0.2 (K562/IMA-0.2) and $1 \mu \mathrm{M}$ (K562/IMA-1) imatinib.

\section{Measurement of cell growth by XTT assay}

The IC50 values (drug concentration that inhibits cell growth by 50\%) of imatinib and PDMP were determined by XTT cell proliferation assay. In short, $2 \times 10^{4}$ cells/well were seeded into 96-well plates containing $100 \mu \mathrm{l}$ of the full medium with increasing concentrations of imatinib and PDMP and then incubated at $37^{\circ} \mathrm{C}$ in $5 \% \mathrm{CO}_{2}$ for $72 \mathrm{~h}$. Then, the cells were treated with $50 \mu 1$ XTT for $4 \mathrm{~h}$, and the plates were read under 492-nm wavelengths by ELISA reader (Thermo Electron Corporation Multiskan Spectrum,Vantaa, Finland) (Piskin et al. 2007).

Measurement of endogenous ceramide levels by lipidomics

The cellular levels of endogenous ceramides were measured using high performance liquid chromatography/mass spectrometry (LC/MS) as described previously (Koybasi et al. 2004). In short, after cells were collected by centrifugation, lipids were extracted directly from cell pellets, and the levels of sphingolipids and inorganic phosphate $(\mathrm{Pi})$ levels in the same extracts were measured as described (Koybasi et al. 2004). The levels of ceramides were normalized to Pi concentrations.

Plasmids and transfections

pcDNA3.1 and pcDNA3.1/GCS plasmids were obtained from Invitrogen, USA. Transfection of human CML cells was performed using an Effectene transfection kit (Qiagen) as described by the manufacturer.

\section{Detection of human GCS mRNA by RT-PCR}

Total RNA was extracted using Rneasy RNA isolation kit (Qiagen) as described by the manufacturer. Using reverse transcriptase (Promega), $1 \mu \mathrm{g}$ of total RNA was reverse transcribed. After $1 \mathrm{~h}$ incubation at $50^{\circ} \mathrm{C}$, the reactions were stopped by $95^{\circ} \mathrm{C}$ heating for $5 \mathrm{~min}$. The resulting total cDNA was then used in PCR to measure the mRNA levels of GCS and beta-actin. The mRNA levels of beta-actin were used as internal control (Ogretmen et al. 2001). The primer sequences and PCR conditions were as follows: GCS-forward (5'ATGACAGAAAAAGTAGGCT3'),GC S-reverse (5'-GGACACCCCTGAG TGGAA- $\left.3^{\prime}\right)$; and beta-actin-forward (5'-CAGAGCAAGAGAGGCATCCT$3^{\prime}$ ), beta-actin-reverse (5'-TTGAAGGTCTCA AACATG AT- $\left.3^{\prime}\right)$. Using these primers, $1 \mu \mathrm{l}$ of the reverse transcriptase reaction was amplified for 35 cycles $\left(94^{\circ} \mathrm{C}, 1 \mathrm{~min}\right.$; $55^{\circ} \mathrm{C}, 2 \mathrm{~min} ; 72^{\circ} \mathrm{C}, 2 \mathrm{~min}$ ) using $\mathrm{Taq}$ DNA polymerase (Qiagen), and their levels were normalized to that of betaactin as described previously (Ogretmen et al. 2001).

Western blot analysis

The protein levels of GCS and beta-actin were detected by Western blot analysis (Sultan et al. 2006). In short, total proteins $(50 \mu \mathrm{g} / \mathrm{lane})$ were separated by $5-15 \%$ SDS-PAGE (Bio-Rad) and blotted onto an Immobilon membrane, and GCS and beta-actin proteins were detected using $1 \mu \mathrm{g} / \mathrm{ml}$ of rabbit polyclonal anti-GCS or beta-actin (Santa Cruz Biotechnology) antibodies, and peroxidase-conjugated secondary anti-rabbit antibody $(1: 2,500)$. The proteins were visualized using the ECL protein detection kit (Amersham Pharmacia Biotech) as described by the manufacturer.

Detection of cell death

Effects of imatinib on cell death in the presence and/or absence of GCS overexpression, or PDMP treatment in K562 versus K562/IMA- 0.2 or K562/IMA-1 cells were examined using trypan blue exclusion and/or flow cytometry, as we described previously.

\section{Results}

One of the mechanisms of resistance to imatinib-induced cell death involves the overexpression of GCS

We previously explored cytotoxic effect of imatinib on imatinib-sensitive and imatinib-resistant K562 cells (Baran et al. 2007). The results revealed that K562/IMA-0.2 and K562/IMA-1 cells showed 2.3- to 19-fold resistance to imatinib, as compared to sensitive cells. The $\mathrm{IC}_{50}$ values of imatinib for K562, K562/IMA-0.2, and K562/IMA-1 cells were 240,565 , and 4,600 nM, respectively (Baran et al. 2007). To examine whether mechanisms by which K562/ IMA- 0.2 and K562/IMA- 1 cells acquired resistance to imatinib-induced apoptosis involves the overexpression of GCS, the mRNA levels of GCS in these cells as compared to their parental sensitive controls were examined by RTPCR (Fig. 1a) and protein levels were detected by western blotting (Fig. 1b). The data in Fig. 1a showed that there were 1.85-fold increases in expression levels of GCS in 

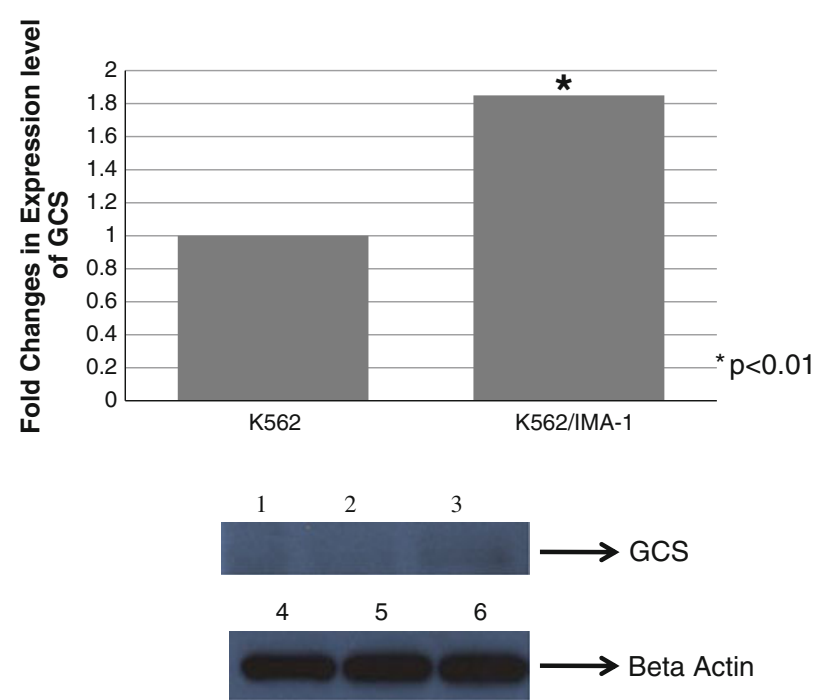

Fig. 1 Expression analyses of GCS in parental versus resistant human CML cells. a GCS mRNA levels in K562 and K562/IMA-1 cells were measured by RT-PCR. Beta-actin levels were used as internal positive controls. Quantification of expression levels of the genes were performed by Quantity One-1D-Gel-Imaging programme (BIORAD). b GCS protein levels in K562, K562/IMA-0.2 and K562/IMA-1 cells (lanes 1,2, and 3) were also measured by western blotting. Beta-actin levels were used as internal

K562/IMA-1 cells as compared to parental sensitive cells. Western blot analysis also confirmed overexpression of GCS in protein levels (Fig. 1b). Beta-actin levels were used as loading controls in Western blotting (Fig. 1b, lower panel, lanes 1-3).

Role of GCS in resistance to imatinib-induced apoptosis

As shown in Fig. 2a, in GCS transfected K562 cells, imatinib significantly prevented cell death (Fig. 2a). Specifically, treatment with 200 and $500 \mathrm{nM}$ imatinib resulted in about 30 and 55\% cell death in response to control vector in K562 cells. On the other hand, in GCS transfected K562 cells, 200 and $500 \mathrm{nM}$ imatinib caused only around 10 and 25\% growth inhibition, respectively (Fig. 2a). The expression levels of GCS in control (vector-transfected) and GCS transfected human K562 cells were confirmed by RT-PCR, and beta-actin levels were used as loading controls (Fig. 2b, lanes $2-3$, and $4-5$, respectively). These data, therefore, demonstrate an important role for GCS in resistance to imatinib-induced cell death in K562 cells.

Analyses of ceramide levels in human CML cells in response to PDMP in the absence or presence of imatinib

The levels of endogenous ceramide in parental and imatinib-resistant K562 cells, treated with PDMP, in the absence
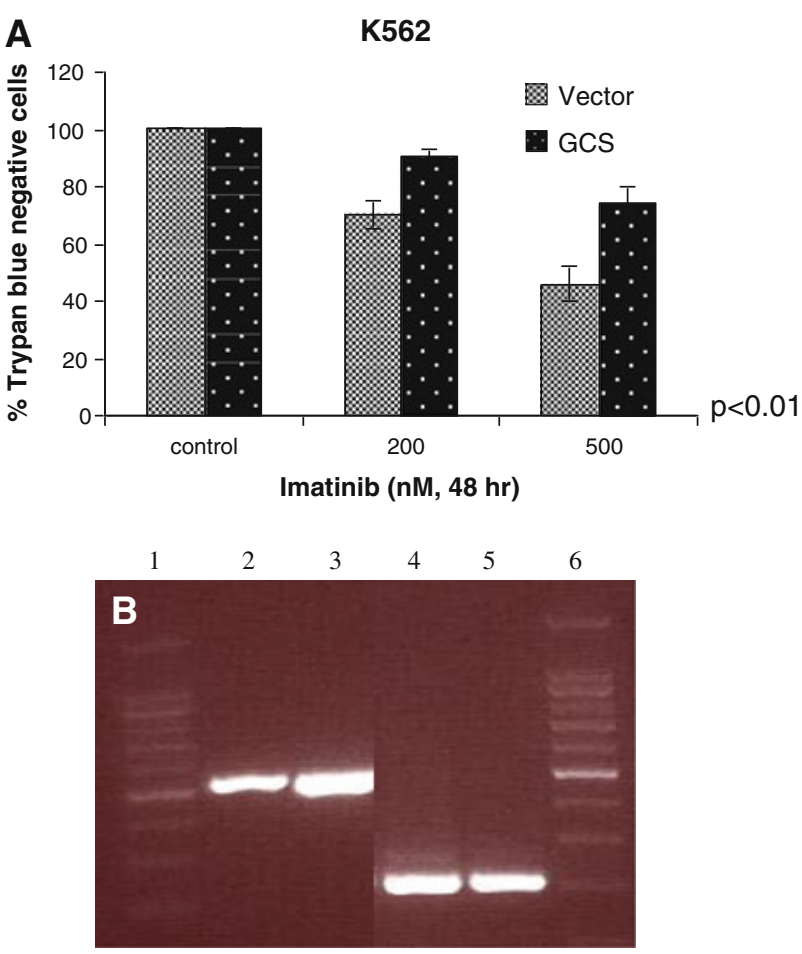

Fig. 2 The role of overexpression of GCS on cell viability in K562 cells. a Percent of cell viability in vector and GCS transfected K562 cells, exposed to 200 and $500 \mathrm{nM}$ imatinib for $48 \mathrm{~h}$, were determined by trypan blue dye exclusion assay. Statistical analysis was done using one way anova, and $P<0.01$ was considered significant. b Expression levels of GCS in vector (lane 2) and GCS (lane 3) transfected K562 cells were measured using RT-PCR. Beta-actin levels were used as internal positive controls (lanes 4 and 5). Lanes 1 and 6 are DNA Ladder

or presence of imatinib (48 h), were measured by LC/MS (Fig. 3a-c). The intracellular levels of ceramides were increased about 2- to 8-fold in K562 and K562/IMA-0.2 and about 2- to 4-fold K562/IMA-1 cells treated with imatinib $(0.2,0.5$ and $2 \mu \mathrm{M}$, respectively). In PDMP exposed K562 cells, the ceramide levels were slightly increased (about 1- to 5-fold). Importantly, in all three K562 sublines, combination of PDMP with imatinib treatment caused significant increases in $\mathrm{C}_{18}$-ceramide levels (35-, 11-, and 6-fold, respectively) in K562, K562/IMA-0.2, and K562/IMA-1 cells, respectively (Fig. 3a-c). Taken together, these data suggest that imatinib induces $\mathrm{C}_{18}$-ceramide accumulation, and targeting GCS using PDMP further enhances its accumulation in K562, K562/IMA-0.2, and K562/IMA-1 cells.

Cell viability analyses of parental and imatinib-resistant K562 cells exposed to GCS inhibitor, PDMP

To examine the involvement of GCS in resistance to imatinib-induced cell death, parental and K562/IMA- 0.2 cells were exposed to PDMP, in the absence or presence of 
Fig. 3 Relative changes of ceramide levels in parental and imatinib-resistant K562 cells treated with PDMP, in the absence or presence of imatinib. The concentrations of $\mathrm{C}_{18: 1^{-}}$, $\mathrm{C}_{14^{-}}, \mathrm{C}_{16^{-}}, \mathrm{C}_{18^{-}}, \mathrm{C}_{20^{-}}, \mathrm{C}_{24^{-}}$, and

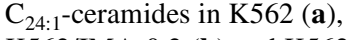
K562/IMA-0.2 (b) and K562/ IMA-1 (c) cells treated with $\operatorname{PDMP}(20 \mu \mathrm{M})$ in the absence or presence of imatinib were measured by LC/MS. The levels of ceramide were normalized to Pi concentrations. Percent changes of the levels of ceramide levels were calculated. The experiments were done in at least two independent trials. Statistical analysis was done using two way anova, and $P<0.01$ was considered significant
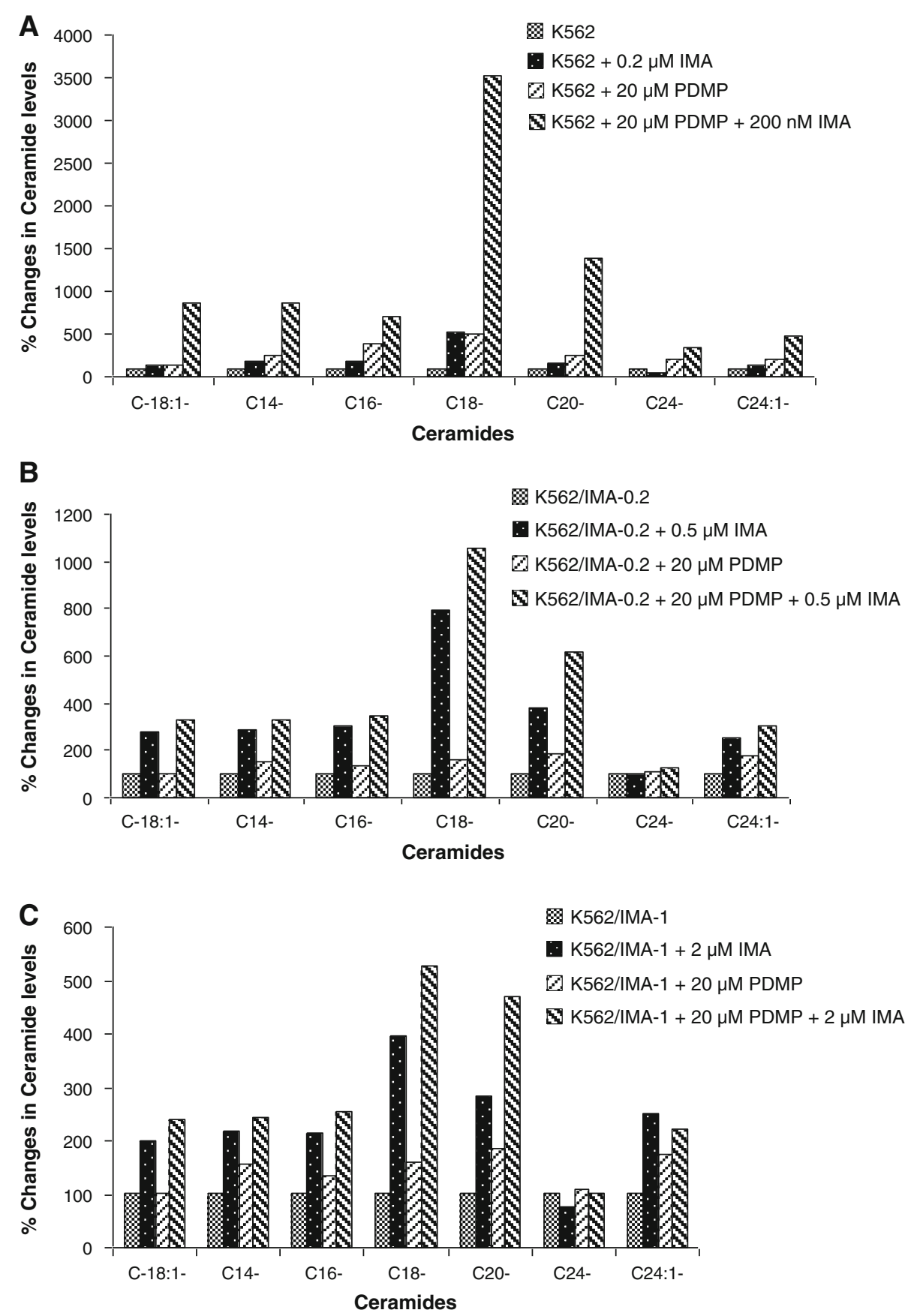

imatinib. K562 cells exposed to $10 \mu \mathrm{M}$ PDMP in the presence of $500 \mathrm{nM}$ imatinib resulted in about $90 \%$ cell death, while $500 \mathrm{nM}$ imatinib, by itself, caused around only $60 \%$ of growth inhibition (Fig. $4 \mathrm{a}$ ). As shown in Fig. 4b, K562/IMA- 0.2 cells exposed to $10 \mu \mathrm{M}$ PDMP in the presence of $500 \mathrm{nM}$ imatinib resulted in about $35 \%$ cell death. Treatment of K562/IMA- 0.2 cells with 500 nM imatinib, by itself, caused around $8 \%$ growth inhibition (Fig. 4b). Ten $\mu \mathrm{M}$ PDMP did not have any effect on K562 or K562/ IMA- 0.2 cells. These data showed that combination therapy of imatinib and PDMP together resulted in higher number of cells in apoptosis as compared to only imatinib exposed cells.

Cell cycle profiles of human CML cells exposed to PDMP in the absence or presence of imatinib

In addition to cell viability analyses, the cell cycle profiles of K562 and K562/IMA-0.2 cells, exposed to PDMP, in the absence or presence of imatinib, were examined for 6,24 , and $48 \mathrm{~h}$ by flow cytometry. The data revealed that exposure to imatinib (200 nM, $6 \mathrm{~h}$ ) did not cause apoptosis in 

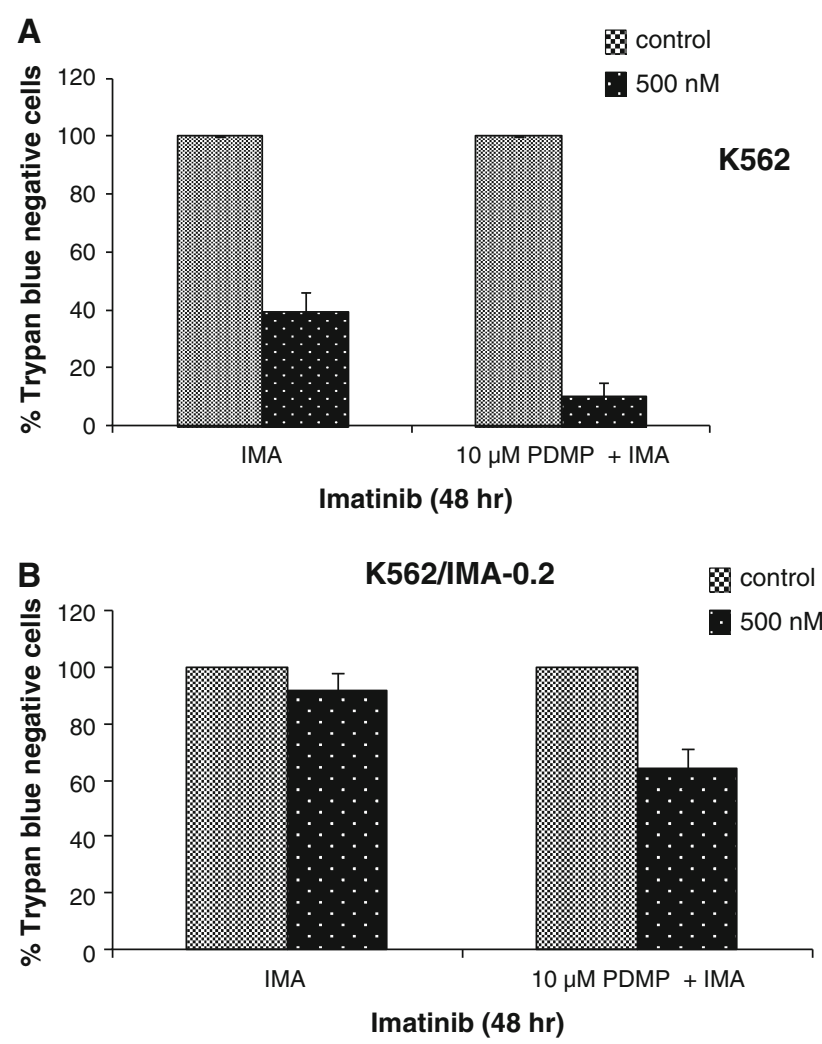

Fig. 4 The role of inhibition of GCS by PDMP on cell viability of K562 and K562/IMA-0.2 cells. Percent changes of cell viability in K562 (a) and K562/IMA-0.2 (b) cells, exposed to PDMP in the absence or presence of imatinib $(500 \mathrm{nM}, 48 \mathrm{~h})$, were determined by trypan blue dye exclusion assay. Experiments were done in duplicates in at least two independent experiments. Error bars represent SD. Statistical analysis was done using two way anova, and $P<0.01$ was considered significant

sensitive K562 cells. Treatment of K562 and K562/IMA0.2 cells with $20 \mu \mathrm{M}$ PDMP in the presence of 200 and $500 \mathrm{nM}$ for $6 \mathrm{~h}$ also did not cause apoptosis. There were also no significant changes in percent of cells in different cell cycle phases (data not shown). Treatment of K562 or K562/IMA- 0.2 cells with PDMP $(20 \mu \mathrm{M})$ in the presence of 200 and $500 \mathrm{nM}$ for $24 \mathrm{~h}$ resulted in 12 and $26 \%$ or 8 and $12 \%$ apoptosis, respectively, while only in imatinibexposed parental and imatinib-resistant K562 cells, there was no apoptosis (data not shown).

The data for $48 \mathrm{~h}$ showed that exposure to imatinib $(200 \mathrm{nM}, 48 \mathrm{~h})$ resulted in 9 and $0 \%$ apoptosis in parental (Fig. 5a) and resistant K562/IMA-0.2 (Fig. 5c) cells, respectively. Imatinib treatment in K562 cells resulted in an increase in G1 and a decrease in G2 and S phases (Fig. 5a). K562 cells exposed to $20 \mu \mathrm{M}$ PDMP and 200 and $500 \mathrm{nM}$ imatinib (48 h) resulted in 20 and $40 \%$ apoptosis, respectively (Fig. 5b). PDMP and imatinib treatment also resulted in an increase in G1-phase, no change in S-phase, and a significant decrease in G2 phase in K562 cells. In case of K562/IMA- 0.2 cells, treatment with $20 \mu$ M PDMP 200 and
$500 \mathrm{nM}$ imatinib $(48 \mathrm{~h})$ resulted in 14 and $22 \%$ apoptosis, respectively (Fig. 5d) while there was no cell in apoptosis in only imatinib applied resistant cells.

Taken together all these data showed that imatinib with the combination of PDMP has much more apoptotic effect on both sensitive and resistant cells. This combination therapy has started to be effective after $24 \mathrm{~h}$ of application. Besides induction of apoptosis, PDMP and imatinib treatment also resulted in cell cycle arrest at G1 phase in K562 cells.

XTT cell proliferation assay in human CML cells exposed to PDMP in the absence or presence of imatinib

The $\mathrm{IC}_{50}$ values of imatinib and the combination therapy of PDMP and imatinib together in K562/IMA-1 cells were determined. The $\mathrm{IC}_{50}$ values of imatinib and combination therapy of PDMP and imatinib were 4,600 and 1,100 nM for K562/IMA-1 cells, respectively (Fig. 6). As shown in Fig. 6, K562/IMA-1 cells, exposed to PDMP and imatinib, expressed about 4-fold more sensitivity, as compared to only imatinib-treated counterparts.

\section{Discussion}

In order to generate imatinib-resistant sub-lines of human CML cell line, K562 were cultured in the presence of gradually increasing concentrations $(0.05-1 \mu \mathrm{M})$ of imatinib over a period of 24 months. However, rare $\mathrm{Ph}$-positive K562 cells were observed, which were unaffected by concentrations of imatinib that suppress the proliferation of most CML cells. These sub-lines with differential sensitivity to imatinib were generated from imatinib-sensitive BCR-ABL-positive human CML cells.

The first important observation from this study was the overall difficulty in generating resistant sub-lines from the parental sensitive cells. Rare survivors could be obtained from high numbers of cells, even when subjected to a gradual exposure to imatinib. These results emphasized the high efficacy and specificity of imatinib in the treatment of BCRABL-positive cells.

Similar approach has been used in various studies to derive imatinib resistance starting with $\mathrm{Ph}$-positive cell lines previously, including AR230, LAMA84, and K562 cell lines (Mahon et al. 2000). Mahon and co-workers were able to grow $\mathrm{K} 562$ cells up to the presence of $0.6 \mu \mathrm{M}$ imatinib concentrations. In this study, K562 cells were able to be grown up to $1 \mu \mathrm{M}$.

Drug resistance could result from elevated levels of the various components of the cell such as GlcCer (Kok et al. 2000; Lucci et al. 1998). Analysis of human tumor specimens revealed elevated GlcCer levels in patients who failed 
B
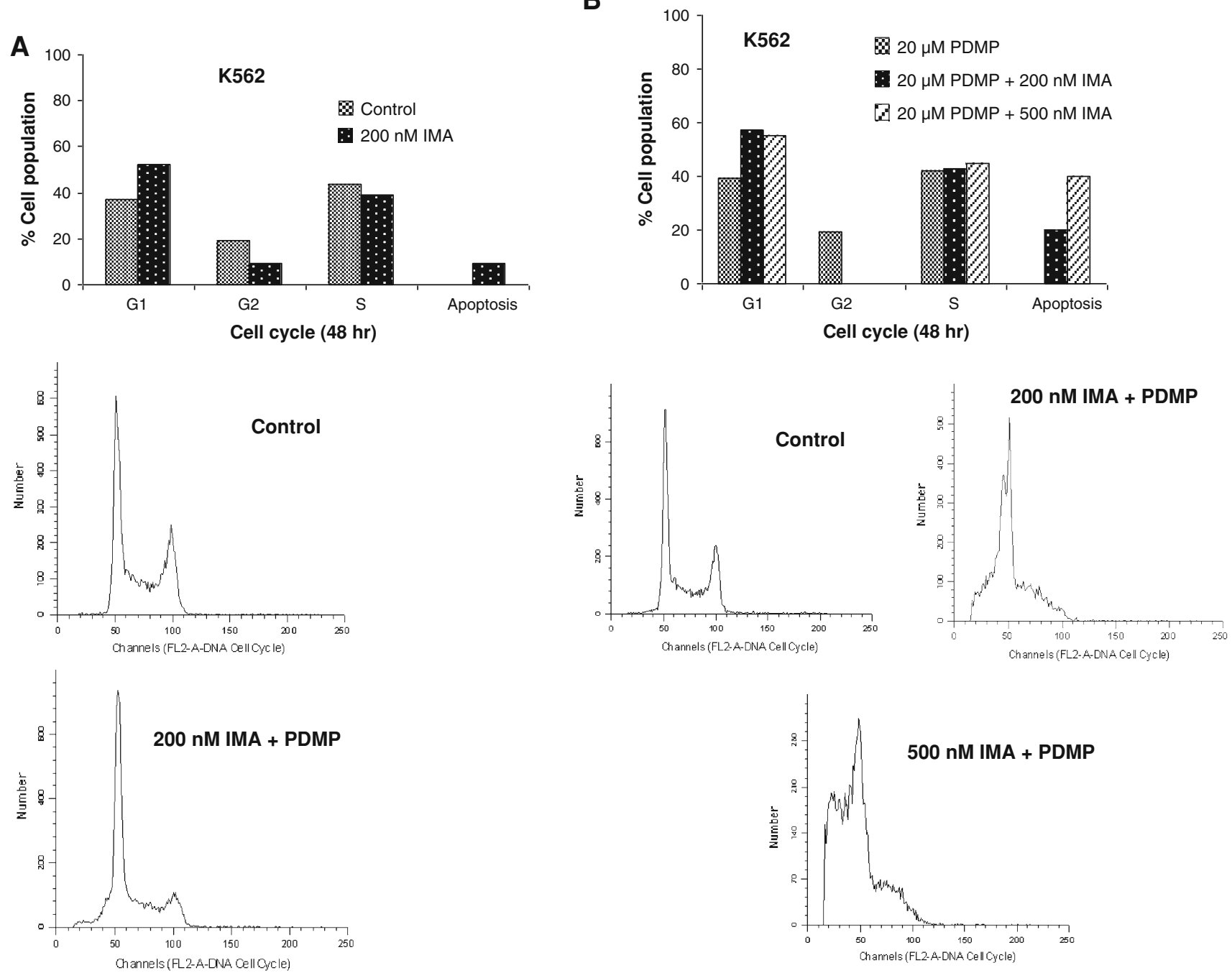

Fig. 5 Cell cycle profiles in K562 cells in response to PDMP. The effects of PDMP $(20 \mu \mathrm{M})$, in the absence or presence of imatinib (200 and $500 \mathrm{nM}$ ), on cell cycle profiles of K562 (a or b) and K562/IMA-

conventional chemotherapy, but GlcCer levels were low in those who responded to treatment (Lucci et al. 1998). Support for the involvement of GCS in drug resistance came from transfection experiments, which showed that overexpression of the enzyme resulted in increased resistance to Adriamycin in drug-sensitive MCF-7 tumor cells (Liu et al. 1999). These results can be interpreted in the sense that MDR tumor cells display an enhanced activity of GCS, which results in accumulation of GlcCer and metabolic removal of ceramide from the sphingolipid pool. In agreement with the previous studies, GCS overexpression has been observed in imatinib-resistant human CML cells, K562/IMA-0.2 and K562/IMA-1, as compared to parental sensitive counterparts.

Our previous data revealed an important role for SK1/ S1P signaling as a major mechanism of imatinib resistance by decreasing ceramide/S1P ratio in CML cells (Baran
0.2 (c or d) were determined using flow cytometry. Statistical analysis was done using two way anova, and $P<0.01$ was considered significant

et al. 2007). The role of SK1/S1P in drug resistance in CML was also confirmed by independent studies (Bonhoure et al. 2008; $\mathrm{Li}$ et al. 2007). In the current study, we increased the intracellular concentrations of ceramide via inhibition of GCS and examined the possibility of enhancing apoptosis in response to imatinib in both sensitive and resistant cells. GCS inhibitors have been found to raise cellular ceramide levels by blocking its conversion into GlcCer and to induce apoptosis (Nicholson et al. 1999; Spinedi et al. 1998). It has previously been demonstrated that PDMP sensitizes murine neuroblastoma cells to Taxol and Vincristine (Sietsma et al. 2000). In this study, PDMPinduced chemo sensitization was investigated in two imatinib-resistant human CML cells. In parallel with the previous data, LC/MS analyses revealed that impairment of ceramide glycosylation by PDMP increased intracellular ceramide levels. On the other hand, cell viability analyses 
C

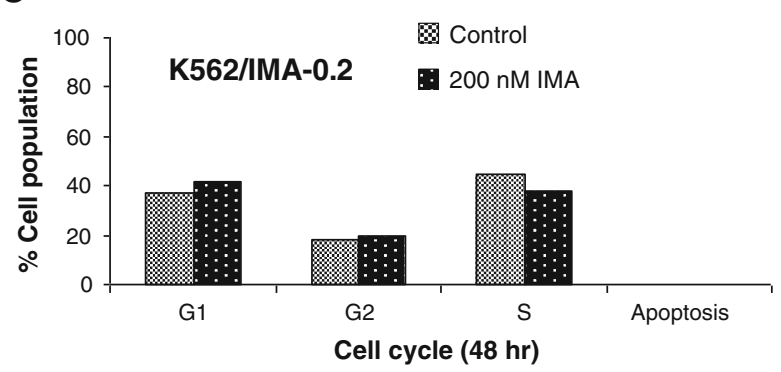

D

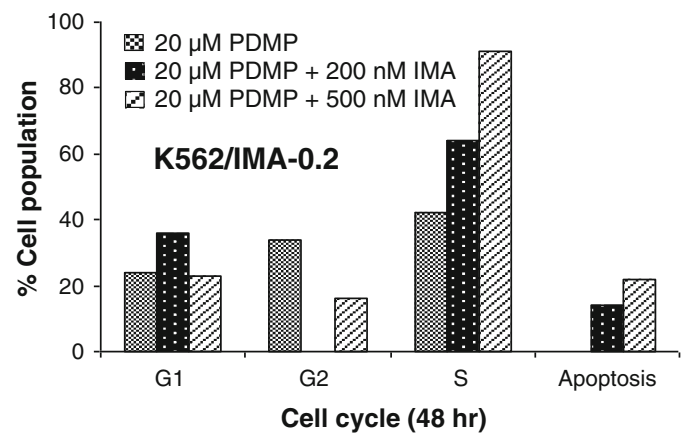

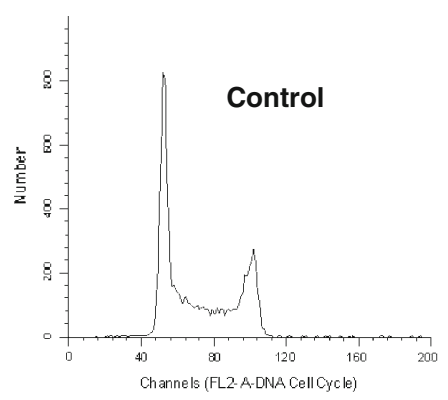

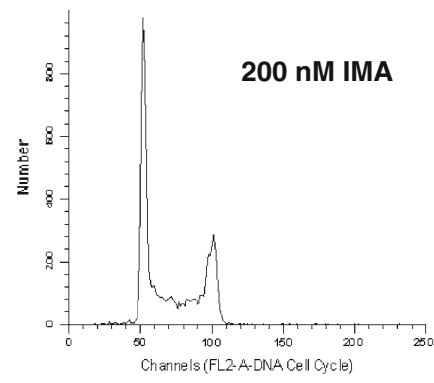

Fig. 5 continued

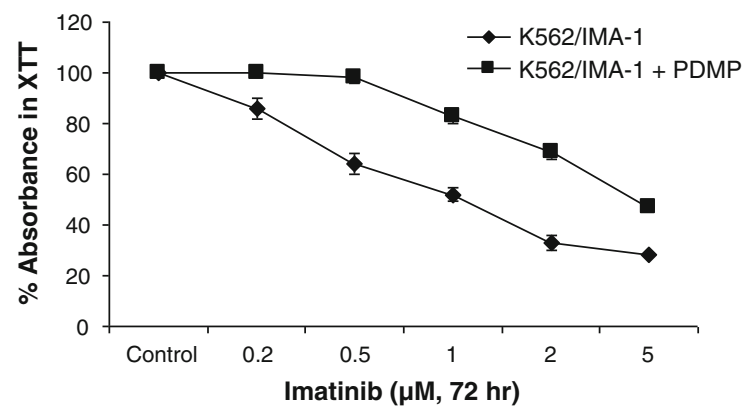

Fig. 6 Effects of PDMP, in the absence or presence of imatinib, on the growth of K562/IMA-1 cells in situ. The $\mathrm{IC}_{50}$ concentrations of imatinib and combination therapy of imatinib and PDMP together were determined by XTT assay for each cell line as described. Experiments were done in triplicate in at least two independent experiments. Statistical analysis was done using two way anova, and $P<0.01$ was considered significant. SD for each point were between 0.5 and $4 \%$. The error bars represent the SD, and when not seen, they are smaller than the thickness of the lines on the graphs

by trypan blue dye exclusion assay and Flow cytometry and cell proliferation analyses by XTT assay also showed that PDMP in combination with imatinib resulted in higher
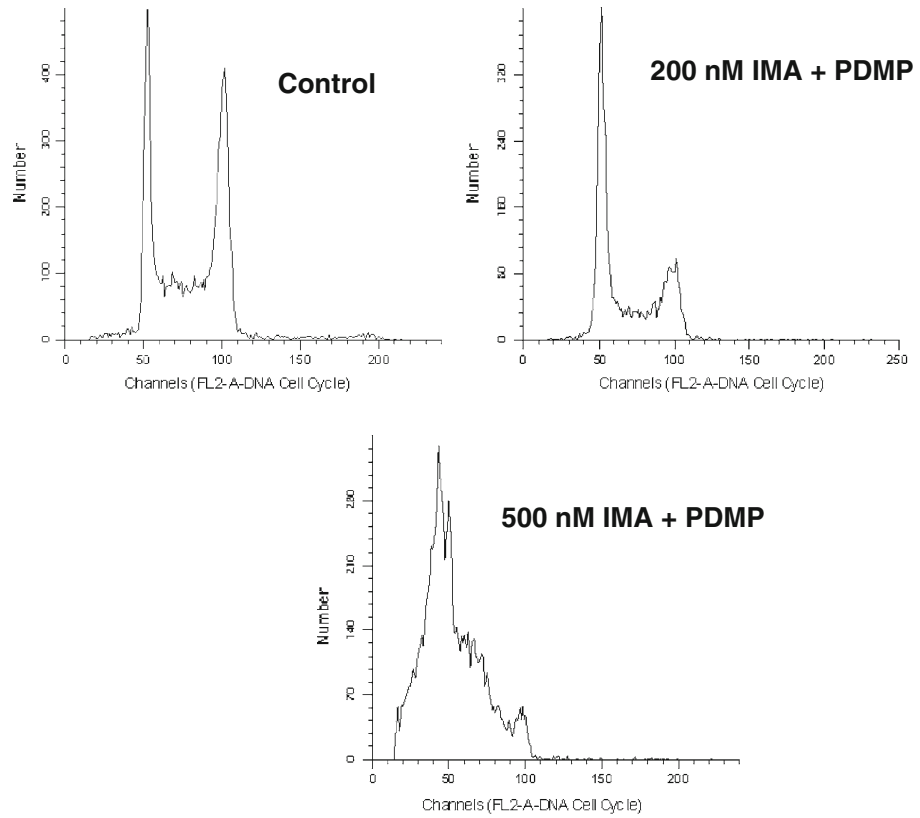

numbers of cells in apoptosis as compared to only imatinib exposed cells. These findings demonstrate the ability to modulate ceramide metabolism should provide a new avenue by which drug sensitivity can be increased in multidrug-resistant cells.

In conclusion, these results show, for the first time, that overexpression of GCS, via increased metabolism of ceramide via conversion to GlcCer, decreasing its cellular accumulation, is involved in the regulation of imatinib resistance in K562 cells, and that this resistance could be overcome, at least in part, by inhibition of GCS, which enhances ceramide accumulation in response to imatinib treatment.

Acknowledgments This work was supported by research grants from the National Institutes of Health to BO (CA-088932, DE-016572, and CA097132).

Conflict of interest We, the authors of the manuscript, do not have any conflict of interest. We alone are responsible for the content and writing of the paper. 


\section{References}

Baran Y, Salas A, Senkal CE, Gunduz U, Bielawski J, Obeid LM, Ogretmen B (2007) Alterations of ceramide/sphingosine 1-phosphate rheostat involved in the regulation of resistance to imatinibinduced apoptosis in K562 human chronic myeloid leukemia cells. J Biol Chem 282:10922-10934

Bonhoure E, Lauret A, Barnes DJ, Martin C, Malavaud B, Kohama T, Melo JV, Cuvillier O (2008) Sphingosine kinase-1 is a downstream regulator of imatinib-induced apoptosis in chronic myeloid leukemia cells. Leukemia 22(5):971-979

Bose R, Verheij M, Haimovitz-Friedman A, Scotto K, Fuks Z, Kolesnick R (1995) Ceramide synthase mediates daunorubicininduced apoptosis: an alternative mechanism for generating death signals. Cell 82:405-414

Bradshaw DM, Arceci RJ (1998) Clinical relevance of transmembrane drug efflux as a mechanism of multidrug resistance. J Clin Oncol 16:3674-3690

Buchdunger E, Zimmermann J, Mett H, Meyer T, Müller M, Druker BJ, Lydon NB (1996) Inhibition of the abl protein-tyrosine kinase in vitro and in vivo by a 2-phenylaminopyrimidine derivative. Cancer Res 56:100-104

Cabot MC, Giuliano AE, Han TY, Liu YY (1999) Sdz psc 833, the cyclosporine a analogue and multidrug resistance modulator, activates ceramide synthesis and increases vinblastine sensitivity in drug-sensitive and drug-resistant cancer cells. Cancer Res 59:880-885

Dbaibo GS, Pushkareva MY, Rachid RA, Alter N, Smyth MJ, Obeid LM, Hannun YA (1998) P53-dependent ceramide response to genotoxic stress. J Clin Invest 102:329-339

Deininger M (2005) Resistance to imatinib: mechanisms and management. J Natl Compr Canc Netw 3:757-768

Hale AJ, Smith CA, Sutherland LC, Stoneman VE, Longthorne V, Culhane AC, Williams GT (1996) Apoptosis: molecular regulation of cell death. Eur J Biochem 237:884

Hannun YA (1996) Functions of ceramide in coordinating cellular responses to stress. Science 274:1855-1859

Hannun YA, Obeid LM (2002) The ceramide-centric universe of lipidmediated cell regulation: stress encounters of the lipid kind. J Biol Chem 277:25847-25850

Hegedus T, Orfi L, Seprodi A, Varadi A, Sarkadi B, Keri G (2002) Interaction of tyrosine kinase inhibitors with the human multidrug transporter proteins, mdr1 and mrp1. Biochim Biophys Acta 1587:318-325

Inokuchi J, Jimbo M, Momosaki K, Shimeno H, Nagamatsu A, Radin NS (1990) Inhibition of experimental metastasis of murine lewis lung carcinoma by an inhibitor of glucosylceramide synthase and its possible mechanism of action. Cancer Res 50:6731-6737

Koca E, Haznedaroglu IC (2005) Imatinib mesylate and the management of chronic myeloid leukemia (CML). Turk J Hematol 2(4):161-172

Kok JW, Veldman RJ, Klappe K, Koning H, Filipeanu CM, Muller M (2000) Differential expression of sphingolipids in mrp1 overexpressing ht 29 cells. Int J Cancer 87:172-178

Kolesnick RN, Kronke M (1998) Regulation of ceramide production and apoptosis. Annu Rev Physiol 60:643-665

Koybasi S, Senkal CE, Sundararaj K, Spassieva S, Bielawski J, Osta W, Day TA, Jiang JC, Jazwinski SM, Hannun YA, Obeid LM, Ogretmen B (2004) Defects in cell growth regulation by c18:0-ceramide and longevity assurance gene 1 in human head and neck squamous cell carcinomas. J Biol Chem 279:4431144319

Krystal GW (2001) Mechanisms of resistance to imatinib (sti571) and prospects for combination with conventional chemotherapeutic agents. Drug Resist Updat 4:16-21
Kyogashima M, Inoue M, Seto A, Inokuchi J (1996) Glucosylceramide synthetase inhibitor, d-threo-1-phenyl-2-decanoylamino-3-morpholino-1-propanol exhibits a novel decarcinogenic activity against shope carcinoma cells. Cancer Lett 101:25-30

Lavie Y, Cao H, Bursten SL, Giuliano AE, Cabot MC (1996) Accumulation of glucosylceramides in multidrug-resistant cancer cells. J Biol Chem 271:19530-19536

Li QF, Huang WR, Duan HF, Wang H, Wu CT, Wang LS (2007) Sphingosine kinase-1 mediates BCR/ABL-induced upregulation of Mcl-1 in chronic myeloid leukemia cells. Oncogene 26(57):7904-7908

Liu YY, Han TY, Giuliano AE, Cabot MC (1999) Expression of glucosylceramide synthase, converting ceramide to glucosylceramide, confers adriamycin resistance in human breast cancer cells. J Biol Chem 274:1140-1146

Liu YY, Han TY, Giuliano AE, Hansen N, Cabot MC (2000) Uncoupling ceramide glycosylation by transfection of glucosylceramide synthase antisense reverses adriamycin resistance. J Biol Chem 275:7138-7143

Lucci A, Cho WI, Han TY, Giuliano AE, Morton DL, Cabot MC (1998) Glucosylceramide: a marker for multiple-drug resistant cancers. Anticancer Res 18:475-840

Mahon FX, Deininger MW, Schultheis B, Chabrol J, Reiffers J, Goldman JM, Melo JV (2000) Selection and characterization of bcr-abl positive cell lines with differential sensitivity to the tyrosine kinase inhibitor sti571: diverse mechanisms of resistance. Blood 96:1070-1079

Marsh NL, Elias PM, Holleran WM (1995) Glucosylceramides stimulate murine epidermal hyperproliferation. J Clin Invest 95:29032909

Myrick D, Blackinton D, Klostergaard J, Kouttab N, Maizel A, Wanebo H, Metha S (1999) Paclitaxel-induced apoptosis in jurkat, a leukemic t cell line, is enhanced by ceramide. Leuk Res 23:569-578

Nicholson KM, Quinn DM, Kellett GL, Warr JR (1999) Preferential killing of multidrug-resistant kb cells by inhibitors of glucosylceramide synthase. Br J Cancer 81:423-430

Ogretmen B, Hannun YA (2004) Biologically active sphingolipids in cancer pathogenesis and treatment. Nat Rev Cancer 4:604-616

Ogretmen B, Schady D, Usta J, Wood R, Kraveka JM, Luberto C, Birbes H, Hannun YA, Obeid LM (2001) Role of ceramide in mediating the inhibition of telomerase activity in a549 human lung adenocarcinoma cells. J Biol Chem 276:24901-24910

Okazaki T, Kondo T, Kitano T, Tashima M (1998) Diversity and complexity of ceramide signalling in apoptosis. Cell Signal 10:685-692

Perales M, Cervantes F, Cobo F, Montserrat E (1998) Non-hodgkin's lymphoma associated with gaucher's disease. Leuk Lymphoma 31:609-612

Piskin O, Ozcan MA, Ozsan GH, Ates H, Demirkan F, Alacacioglu I, Undar B (2007) Synergistic effect of imatinib mesylate and fludarabine combination on Philadelphia chromosome-positive chronic myeloid leukemia cell lines. Turk J Haematol 24:23-27

Robertson LE, Chubb S, Meyn RE, Story M, Ford R, Hittelman WN, Plunkett W (1993) Induction of apoptotic cell death in chronic lymphocytic leukemia by 2-chloro-2'-deoxyadenosine and 9beta-d-arabinosyl-2-fluoroadenine. Blood 81:143-150

Sawai H, Okazaki T, Takeda Y, Tashima M, Sawada H, Okuma M, Kishi S, Umehara H, Domae N (1997) Ceramide-induced translocation of protein kinase c-delta and -epsilon to the cytosol implications in apoptosis. J Biol Chem 272:2452-2458

Sietsma H, Veldman RJ, Kolk D, Ausema B, Nijhof W, Kamps W, Vellenga E, Kok JW (2000) 1-phenyl-2-decanoylamino-3-morpholino-1-propanol chemosensitizes neuroblastoma cells for taxol and vincristine. Clin Cancer Res 6:942-948 
Spinedi A, Bartolomeo SD, Piacentini M (1998) Apoptosis induced by n-hexanoylsphingosine in chp-100 cells associates with accumulation of endogenous ceramide and is potentiated by inhibition of glucocerebroside synthesis. Cell Death Differ 5:785-791

Sultan I, Senkal CE, Ponnusamy S, Ponnusamy S, Bielawski J, Szulc Z, Bielawska A, Hannun YA, Ogretmen B (2006) Regulation of the sphingosine-recycling pathway for ceramide generation by oxidative stress, and its role in controlling c-myc/max function. Biochem J 393:513-521

Walz C, Sattler M (2006) Novel targeted therapies to overcome imatinib mesylate resistance in chronic myeloid leukemia $(\mathrm{cml})$. Crit Rev Oncol Hematol 57:145-164 